\title{
MARKET AND DEVELOPMENT TRENDS IN COGENERATION AND COMBINED HEAT AND POWER PLANTS
}

\author{
Jan SlaD*, Andreas Pickard, Frank Strobelt
}

\author{
Siemens AG, Freyeslebenstr.1, 91058 Erlangen, Germany \\ * corresponding author: jan.slad@siemens.com
}

\begin{abstract}
The transition of energy mix in Europe is placing greater focus on energy efficiency. Lawmakers in some of EU countries have already recognized that combined heat and power generation (cogeneration, CHP) can help increase energy efficiency. Targeted promotion and subsidization have raised the cost-effective profitability of cogeneration plants significantly. But how can the economic value of this investment be maximized?
\end{abstract}

KEYWORDS: CCPP, CHP, power plants, cogeneration, repowering, gas turbines, operational flexibility, efficiency, power market.

\section{INTRODUCTION}

As concerns grow about environmental protection, global warming, and steadily rising energy prices, public interest is focusing more on energy efficiency. Germany is promoting and subsidizing efforts to expand the use of renewable energy, better building insulation, and cogeneration to make power and heat supply systems more energy-efficient. Current subsidy legislation, driven by economics and defined energyefficiency and climate protection goals, is aimed at expanding combined heat and power generation to the extent that 25 percent of the nation's electric power will be produced by cogeneration plants by the year 2020.

Yet even as lawmakers recognize the significant contribution made by cogeneration to increasing energy efficiency, there are ongoing discussions about whether these subsidies make good sense. The doubters, in most cases, are contrasting figures and data that make no sense in comparative analyses, pitting, for example, the energy utilization factors of cogeneration plants against the electrical efficiency of plants generating purely electric power. Ultimately, it is the efficiency of the systems in our energy supply network that are the decisive variable. When electricity has to be generated from fossil fuels because currently available renewable energy sources are unable to completely meet the demand, waste heat is generated that is discharged to the environment without being utilized. According to publications, cogeneration enables fuel savings of anywhere from 10 to 20 percent compared with the separate generation of heat and power. It should also be noted that the theoretical savings potential is actually much higher. In theory, design and operation would always strive for optimized pairing of heat and power generation, entirely ruling out the possibility for peak-load heat generation from direct-fired boilers. In industrial plants, savings potentials of up to 40 percent are readily achievable, because in most cases the consumption of heat and electric power remains relatively constantand enables a narrow optimization window.

\section{WHAT DOES COGENERATION ACTUALLY MEAN?}

Cogeneration is understood to mean the simultaneous production of electricity and heat, with the latter generated for building heating or production processes. There is a very broad range of designs for cogeneration power plants, depending on the required generating capacity and the fuel being fired and transformed into useful energy.

In the case of liquid or gaseous fuels, combined cycle processes have become the state of the art, in which a downstream water-steam cycle utilizes the waste heat from a topping cycle with internal combustion, e.g. a gas turbine or a gas engine (diesel- or gas-fired). As illustrated in figure 1, the exhaust gases are then routed to a heat-recovery steam generator to produce steam or hot water. Steam produced from this recovered waste heat can be used to drive a downstream steam turbine to generate more electric power before the steam is extracted for heating purposes.

Particularly in combined cycle power plant designs where a gas turbine serves as the primary cycle, the temperature for steam production in the heat-recovery steam generator is at a level that lends itself well to first allowing the steam to expand through a steam turbine to generate electric power before it is subsequently extracted for process steam or heating purposes. This combined cycle design concept allows the production unit to achieve electrical efficiency ratings of over 60 percent when used solely to generate electric power without steam extraction.

When firing solid fuels like lignite and bituminous coal, it is more common to implement a conventional water-steam rankine cycle in which steam is generated in a direct-fired boiler. When operated solely in power generation mode, these types of plants can de- 


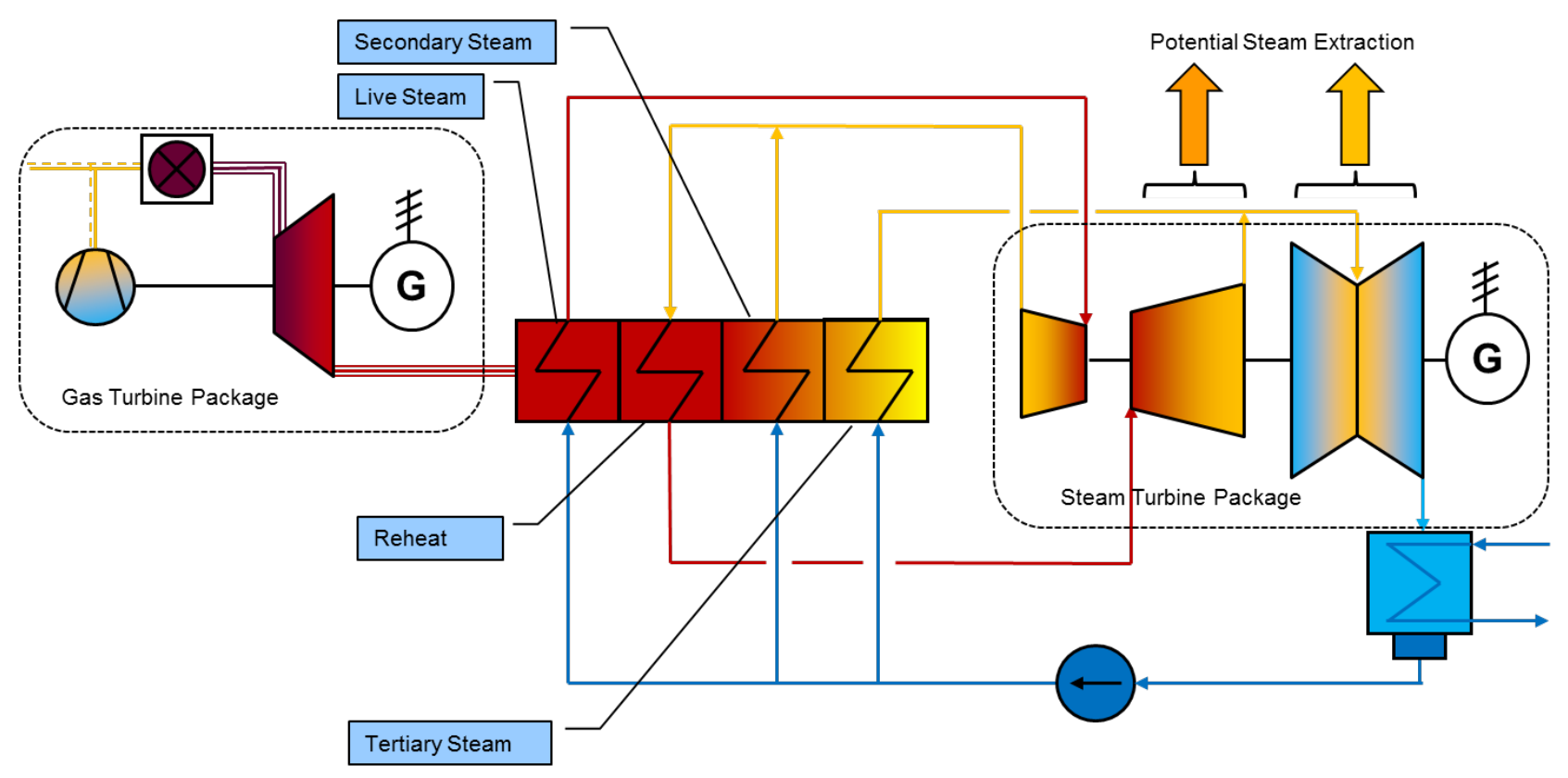

FiguRE 1. Triple pressure reheat cogeneration cycle (simplified).
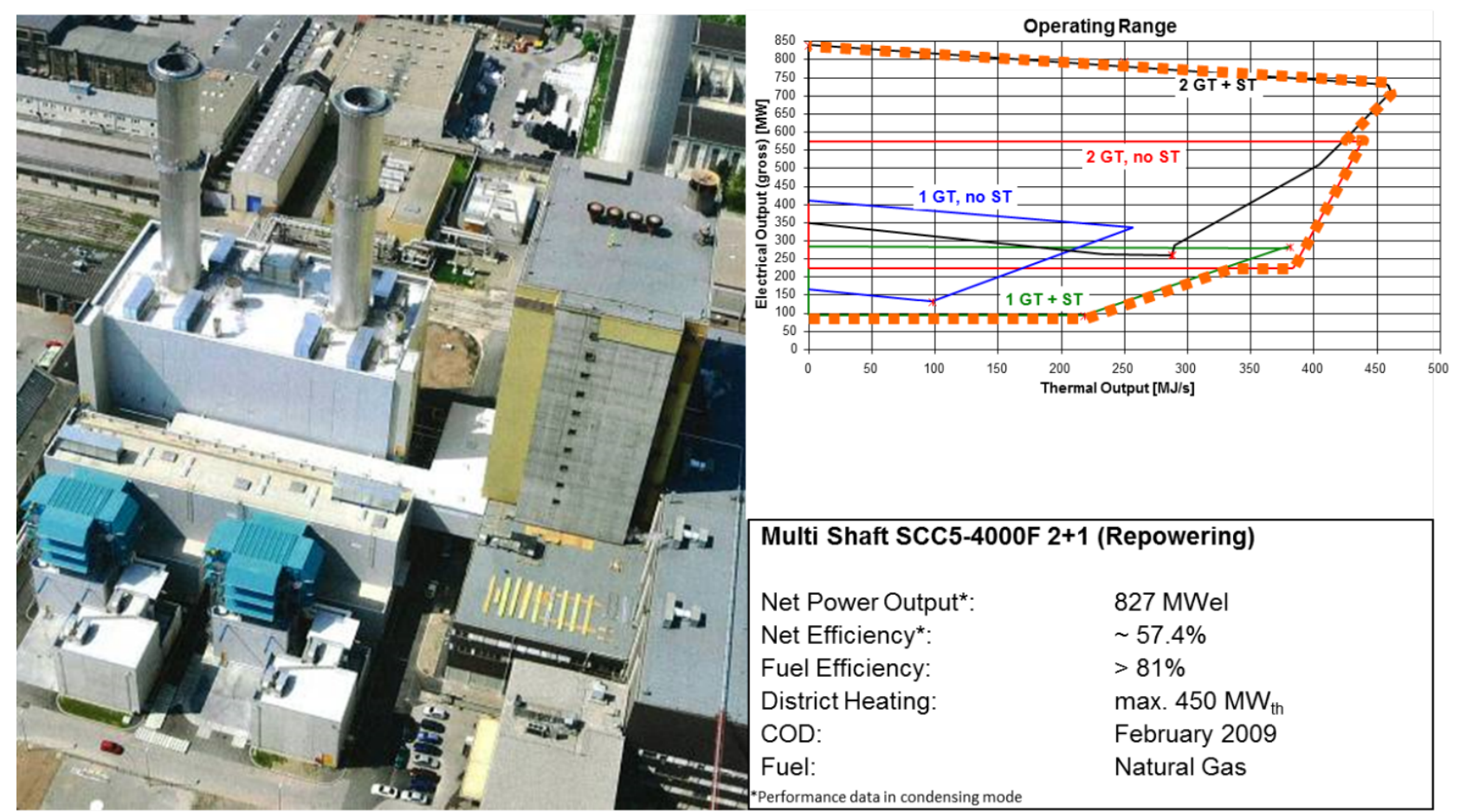

Figure 2. Simmering Power Station (repowered), Vienna, Austria. 


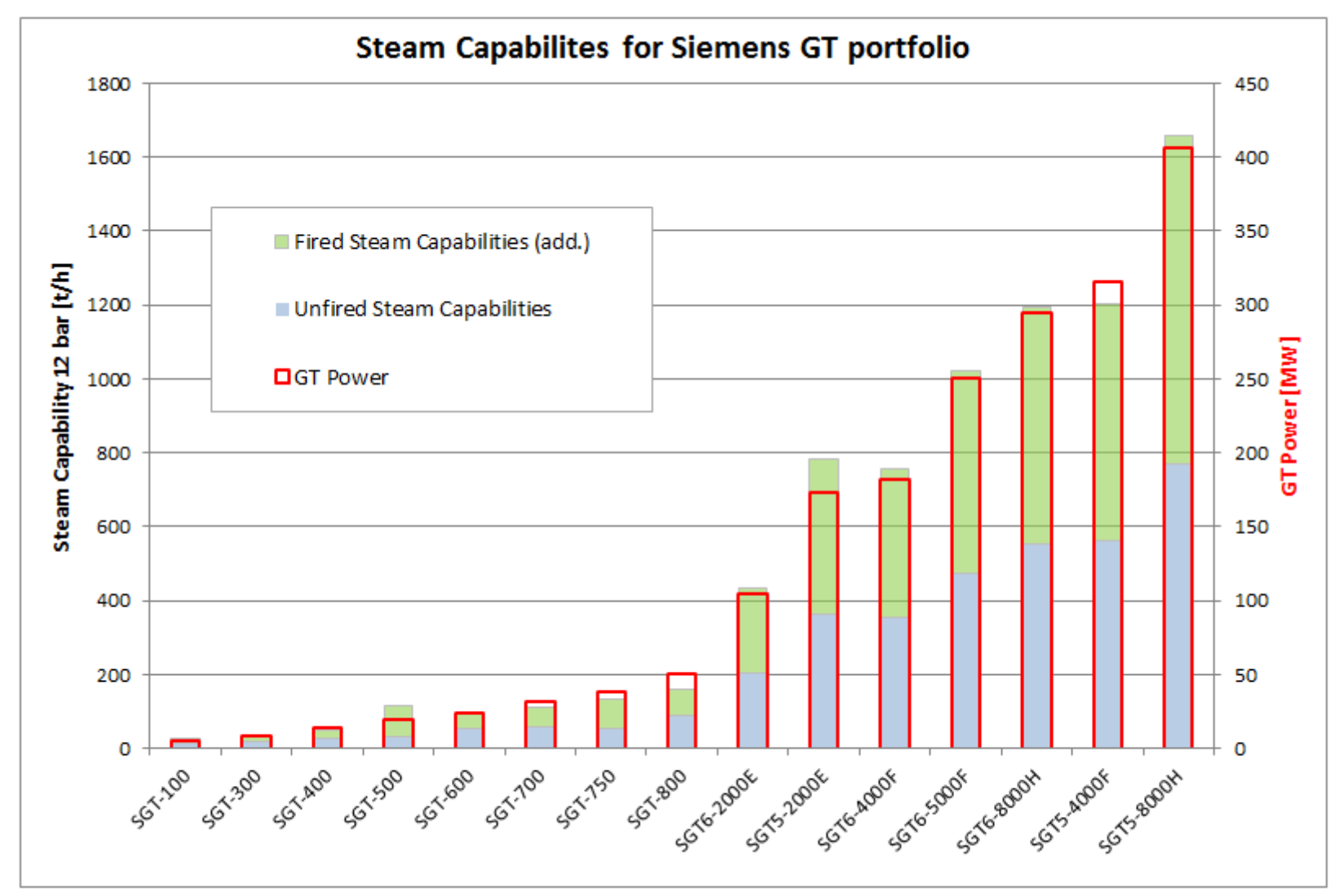

Figure 3. Steam capabilities for Siemens gas turbines.

liver electrical efficiencies well below 50 percent. Their maximum efficiency is thus significantly lower than that of a state-of-the-art combined cycle power plant. What's more, the high carbon content of the coal fuel generates much higher $\mathrm{CO}_{2}$ emissions. These plants therefore fail to fulfill the subsidization criteria stipulated by lawmakers in Germany's Combined Heat and Power Act. Instead, some plants have modernized by backfitting an upstream gas turbine to create a combined cycle configuration. Simmering Power Station in Vienna, Austria (see Figure 2) has been repowered to a combined cycle configuration to improve overall cost-effectiveness and reduce emissions.

\section{PERFormance Classes FOR EVERY APPLICATION}

In the small power classes below $5 \mathrm{MW}$, standard packaged solutions predominate, for which only peripherals need be adjusted to project-specific conditions, but nothing within the package is altered. In most cases, a gas- or diesel-fired engine of this power class is combined with a simple heat-recovery system to provide hot water in a combined heat and power configuration. Above the $5 \mathrm{MW}$ power range, plant design concepts are increasingly being optimized and customized as needed for specific applications. Where a gas turbine is used, a combined cycle configuration is usually selected that incorporates a steam turbine running the water-steam cycle. Siemens' gas turbine portfolio ranges from the SGT-100 series - which, via the steam turbine, delivers heating steam at up to $25 \mathrm{t} / \mathrm{h}-$ to the SGT5-8000H series that has steam capabilities up to $1,100 \mathrm{t} / \mathrm{h}$ in a $1 \times 1$ arrangement.

Due to their basic design, industrial-class units are generally configured with simple water-steam cycles. Up to gas turbine outputs of about $50 \mathrm{MW}$, conventional solutions implement a heat-recovery steam generator (HRSG) with only one evaporator stage and no reheat section (single-pressure HRSG) as illustrated in figure 4. While this design may keep investment costs down, it is accompanied by a simple waste-heat recovery and lower efficiency ratings. This performance class is normally found in small-town settings or small industrial facilities.

Where higher thermal or electrical generating capacities are needed, it is recommendable to opt for higher-performance unit designs. Larger plants not only deliver greater efficiency benefits due to their turbine's design (the jump from D-Class gas turbines to E-Class), but the specific investment costs are also lower (based on economies of scale).

In general, the higher the performance class, the greater the complexity of the water-steam cycles for increasing fuel efficiency. Unit outputs of up to $170 \mathrm{MW}$ are typically paired with double-pressure HRSGs, most without reheating shown in figure 5.

Above $170 \mathrm{MW}$, triple-pressure HRSGs equipped with reheat section are usually used. As the number of 


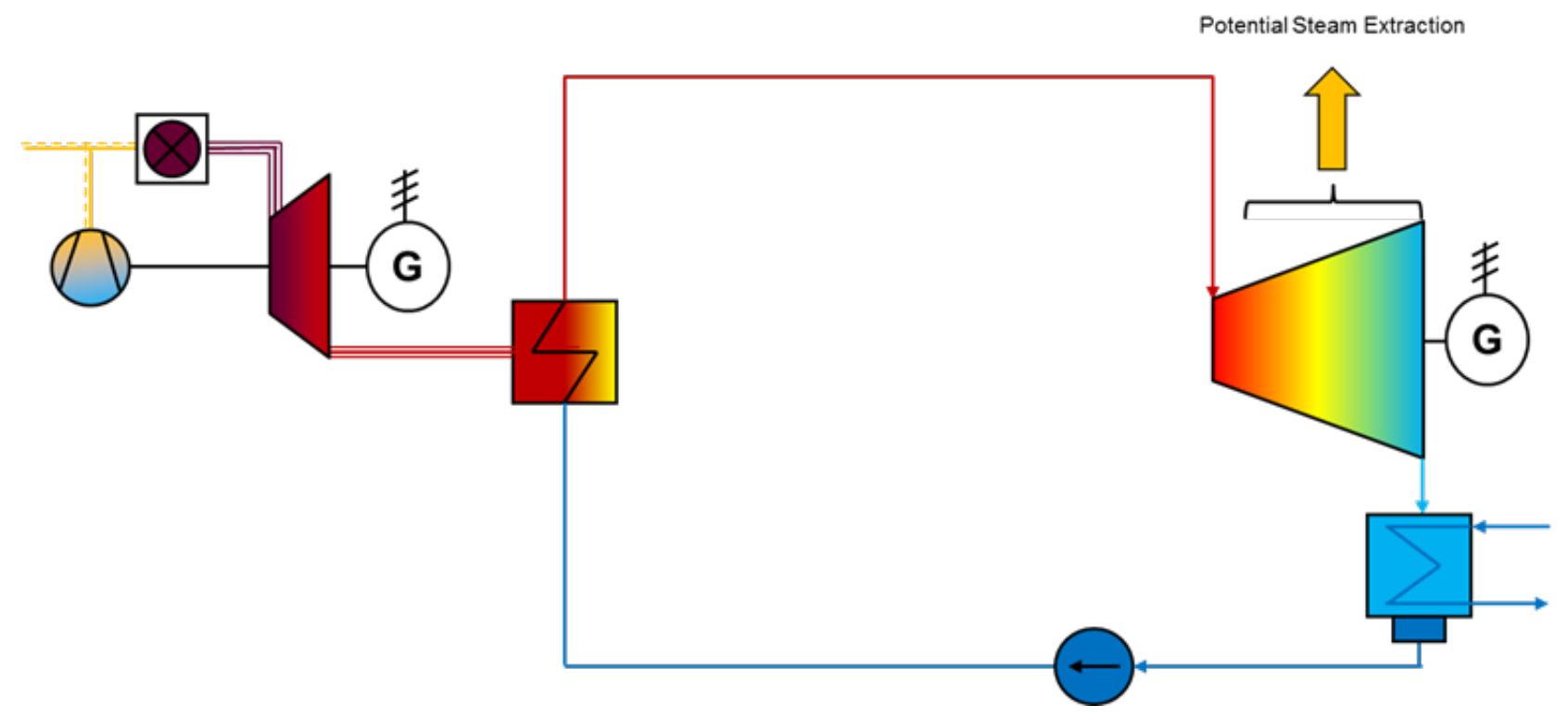

Figure 4. Single Pressure CHP Cycle (simplified).

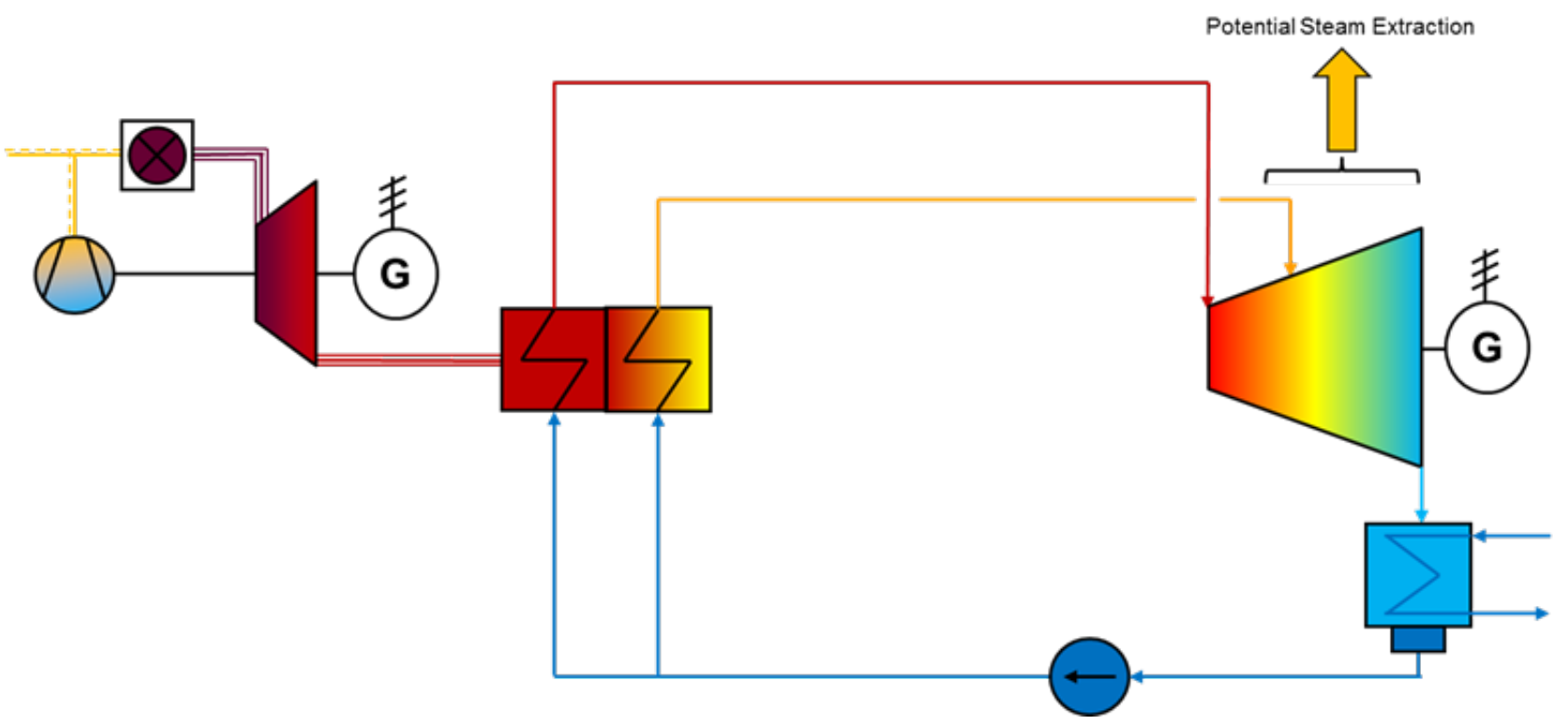

Figure 5. Double Pressure Non Reheat CHP Cycle (simplified).

evaporator stages grows, and with the inclusion of a reheat section, the utilization of a gas turbine's exhaust gas improves in the Rankine cycle of the water-steam cycle - and so does overall plant efficiency. However, it is the customer's own performance assessment that ultimately decides how complex the design of the water-steam cycle should be, and what is economically justifiable in designing the heat-recovery steam generator.

To supply heat to larger industrial complexes or within major cities with a high population density, solutions on the scale of large power plants are viable. In these environments, electrical generating capacities in the range of $600 \mathrm{MW}$ or more and thermal outputs of $370 \mathrm{MW}$ per gas turbine can be achieved. These plant designs can achieve energy efficiency ratings of 85 percent while simultaneously attaining electrical efficiency of over 61 percent when operating solely in power-generation mode.

\section{Plant Designs optimized For SPECIFIC APPLICATIONS}

The design concept of combined heat and power plants depends primarily on the requirement profile of the heat consumers. Those requirement profiles show quite a variation driven by ambient conditions and seasonal heat demands. However, once the design of a combined heat and power plant is fixed and optimized for a specific requirement profile electric power production and heat provision cannot be controlled and operated independently of one another. Alternatively, it is possible to provide variable steam extraction points within a conventional fossil-fuel combined cycle 
configuration. This allows the plant to be used solely for power generation, if so desired. The advantages of both options are defined in greater detail below.

\section{Plant Designs for heat-Driven OPERATION - ELECTRIC POWER AS A BY-PRODUCT}

In industrial plants where energy production is primarily focused on supplying heat, and the electric power generated is consumed within the facility as a by-product, a heat-driven design is often implemented with a back-pressure steam turbine. In order for combined heat and power plants to be optimally designed in thermodynamic terms, it is ideal if the heat to be generated varies as little as possible in thermal output and temperature. In this case, a process would be selected in which the steam is allowed to expand precisely to those parameters needed by the heat consumer.

Design concepts using back-pressure steam turbines (see figure 66) benefit on the one hand from the fact that effectively no heat is discarded in the steam turbine condenser or transferred to the cooling water, and all thermal energy released from condensation in the heating condensers is routed away as useful heat while at the same time the achievable electrical output of the steam turbine declines because the enthalpy gradient of the turbine is significantly less due to the higher back pressure. The relationship between power generation and heat provision depends directly on the steam turbine's back pressure (driven by the supply temperature demand), and lies between the values for extraction condensing solutions and those without a steam turbine.

If process steam lines of different steam parameters are required, steam turbine extraction points are ideally implemented in a cascading design. These steam turbine extractions can be designed as controlled extraction points or as uncontrolled extraction ports, depending on the range of fluctuation of extractions and pressures. In addition, the process steam lines can be supported by direct extractions bled from an appropriate location in the heat-recovery steam generator.

The fact that the amount of electric power that it's possible to generate depends on the amount of thermal energy to be supplied translates into a loss of operating flexibility, and can constitute an economic disadvantage for power plants participating in the electricity market. In heat-driven operation, electric power is merely a marketable "by-product." To counter this disadvantage, when requirements for power and heat fluctuate widely independent of one another, design concepts with extraction condensing turbines are needed, as described in the next section.

\section{Plant DESIGNS FOR POWER-DRIVEN OPERATION - SUPPLYING ELECTRIC POWER AND HEAT ON DEMAND}

While cogeneration plants have traditionally been designed for heat-driven operation, today plants are making greater use of condensing turbines in order to maximize energy efficiency at the nominal point. This trend is being driven by the increasing use of renewable energy sources and the associated high requirements placed on power plant flexibility for generating power. The weather-dependent volume of electric power fed in from renewable energy sources determines the feedin price and, via the merit order, the dispatch and therefore electricity production (hours of full-load operation) of power plants. It is therefore becoming increasingly important to decouple power supply from heat supply.

Achieving this separation generally involves designing the steam turbine conventionally solely for powergeneration operation. To supply heating steam, appropriate extraction points are provided that can be located e.g. on the low-pressure (LP) turbine section, on the crossover line between the intermediate-pressure (IP) turbine section and LP turbine section, and on the IP turbine section. Steam extractions from the high-pressure (HP) turbine section are quite rare.

The plant design concept selected also determines the ratio between power generation and heat supply. In plants equipped with extraction condensing turbines, this ratio is about 1.4 (in the corresponding load case). One factor that limits the maximum steam extraction is the required cooling steam flow in the low-pressure sections of the steam turbines, which is not available for heat or steam provision. In the decoupled low-pressure section, the power-to-heat ratio is approximately 1.3. This means that the unit's thermal output and efficiency increase by about 10 percent when the LP sections are decoupled.

When the steam turbine is fully decoupled, the power-to-heat ratio is less than 0.8 . In the latter case, the gas turbine alone is generating electricity. The exhaust gas from the gas turbine is transformed in the HRSG to useful heat at an efficiency rate greater than 85 percent. The efficiency of the HRSG can be increased to over 90 percent in the cold boiler section by implementing hot-water district heat exchangers.

\section{Forecasting market tREnds tO OPTIMIZE THE ECONOMIC VALUE OF COGENERATION PLANTS}

The transition of our energy mix to integrate power generation from regenerative energy sources is changing the business model of fossil-fired power generation and heat supply systems. Determining what future cogeneration plants will look like requires in-depth tracking and analysis of developments on the power exchanges, including the control reserve markets, and the derivation of anticipated trends. 


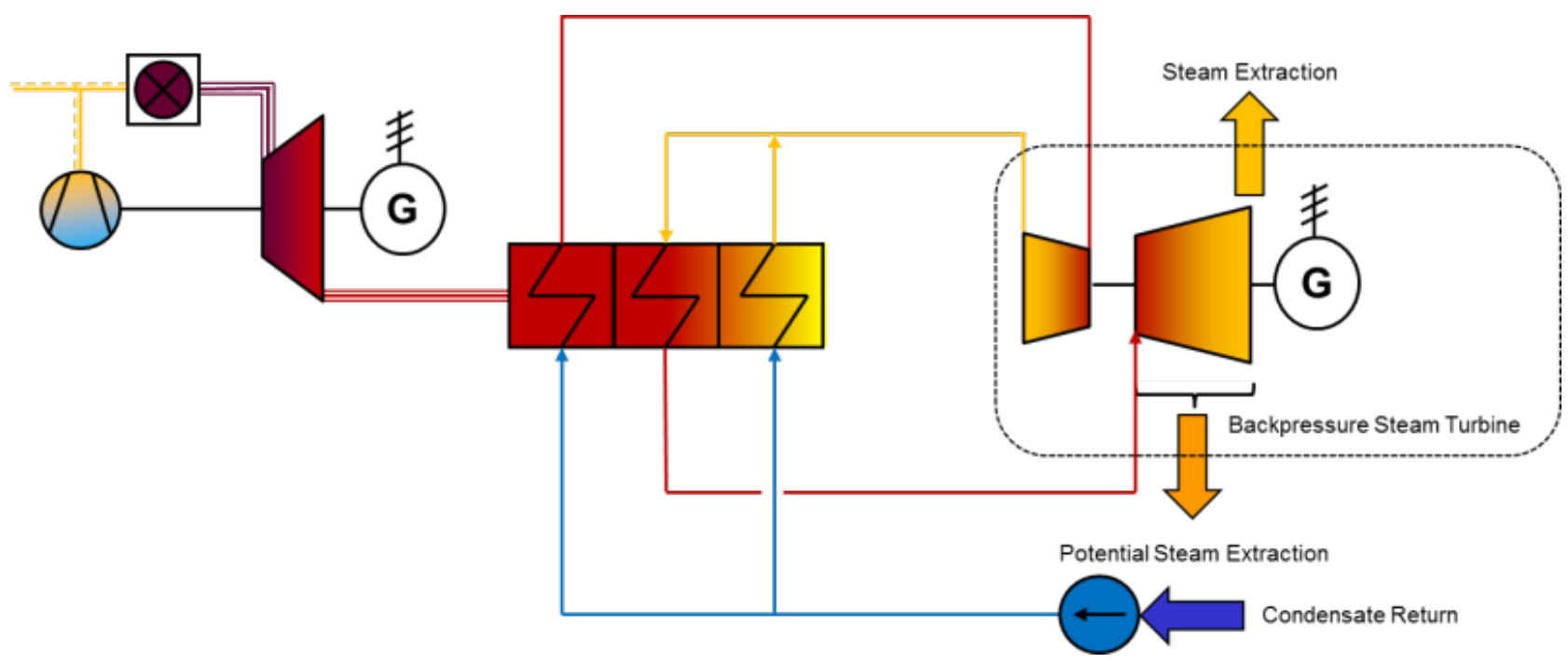

Figure 6. Backpressure Double Pressure Reheat CHP Cycle (simplified).

As a result of the ongoing transition in our energy mix, wind and photovoltaic power are pushing fossilfuel power generation out of the base-load market. Most cogeneration plants are still being operated to meet base-load demand in phases when heat is needed. Due to the steadily growing power feed-in from renewable energy sources, in the future cogeneration plants will also be pushed step by step from continuous fullload operation into low partial-load segments or even to standby operation.

Just how important it is to be able to decouple power supply from heat supply is demonstrated by the fact that existing plants are backfitting thermal energy storage systems, usually in the form of atmospheric hot-water storage tanks. An oil tank on the grounds of Timelkam Combined Cycle Power Plant in Austria, for example, has been converted into an atmospheric hot-water storage tank. These energy storage systems are heated using whatever form of energy happens to be economically available, and then used to supply heat to consumers on demand. This enables a significant increase in plant flexibility with respect to decoupling electric power from heat. When demand for heat is high, the heat load can be controlled via the storage system nearly independent of power production. Power generation, in turn, can orient itself directly to market demand and attractive electricity prices, because it is no longer an uncontrolled by-product.

\section{INTERMEDIATE-LOAD OPERATION - PERIODS OF SHUTDOWN ARE GETTING LONGER}

The $t$ transition of our energy mix is increasingly pushing fossil-fuel power plants out of the base-load market. Soon or later this same trend will also impact cogeneration plants. There will be a growing focus on enhancing operational flexibility when optimizing these plants.
Current forecasts project that phases at full-load operation will steadily shorten while standby phases grow longer. Because the plant systems must operate in order to be able to supply heat, the operating regime becomes a critical factor with respect to periods of plant shutdown: The plant must recommence rotating operation at the very latest when its thermal storage systems have been bled empty. Where needed, units will need to be operated at partial-load in order to be able to ensure heat supply.

For the plant's business model, this means that sales from intermediate-load operation will come under intense pressure. All in all, the number of operating hours will drop below the 5,000-hour marker that used to be considered normal in this operating mode. A precise forecast of the hours of full-load operation must be determined individually for every new unit installed and per fiscal year. Siemens has developed a forecasting tool for this purpose that is capable of projecting probable operating regimes over the coming years for plants located in Europe.

When regular startup and shutdown procedures are planned, fuel consumption can be significantly reduced by optimizing these phases of transient operation. The "Co-Start" startup feature, for example, can shorten the startup process under hot operating conditions to well under 30 minutes, and thereby increase the average efficiency of startup operations by 14 percentage points.

Our Co-Start technology enables plant operators to start their units quickly and efficiently under hotstart conditions: in other words, to re-start units after periods of shutdown that typically last eight hours or less. We can therefore reduce fuel costs during the startup phase and increase plant responsiveness to rapidly changing market conditions, enabling plant operators to start units rapidly and precisely at that point in time when favorable market conditions are in effect. 
We've successfully reduced startup time under hotstart conditions by starting the gas and steam turbines simultaneously - contrary to conventional startup procedures for combined cycle units. The gas turbine starts and runs up, increasing its output at the steepest possible gradient right up to gas turbine full load, without waiting for a staggered startup of the steam turbine, as is customarily practiced. This means that inefficient waiting periods and hold points are made a thing of the past. Intermediate-pressure steam is admitted to the steam turbine from the heat-recovery steam generator as early as possible, which supports the startup process. Steam is not admitted to the high-pressure section of the steam turbine until later in the startup process. In addition, the bypass stations are closed early in the process to support pressure buildup and steam production in the HRSG. This new hot-start procedure using the Co-Start solution is managed by improved instrumentation and controls.

Warm starts - unit re-start after a weekend shutdown that typically lasts up to 48 hours - have also been accelerated using our Co-Start technology.

The improved startup procedure is basically achieved by implementing the same technical measures and modifications to the startup process as for hot starts, the only difference being the different temperature and pressure conditions in the heat-recovery steam generator taken into account by the instrumentation and control system after the longer period of shutdown. Despite extensive acceleration of these startup processes, component service life is not adversely impacted to a prohibitive degree.

Flexible power plants should enable operators not only to start up units quickly, but also to shut them down again just as rapidly so that the operator can respond immediately to electricity market prices that are changing unfavorably or to reduced production demand across the market.

To accelerate the shutdown process, we use our Quick-Stop technology, which fundamentally changes the unit shutdown sequence. Just like the fast starts enabled by our Co-Start feature, the gas turbine is shut down as quickly possible independent of the steam turbine and without the customary waiting periods and hold points observed in conventional combined cycle power plant operations. At the same time, improved instrumentation and control logic operations enable the steam turbine to commence shutdown very early. Another innovative feature comes to bear for single-shaft power plant configurations where the gas turbine, steam turbine, and generator are arranged along a single common shaft by means of couplings. Once the steam turbine has been braked to under 25 revolutions per minute, the coupling opened at the beginning of the shutdown procedure between the gas and steam turbine is rejoined, so that now the additional heavy mass of the gas turbine and the entire shaft train contributes to bringing the steam turbine to a standstill more quickly.

\section{PEAK-LOAD OPERATION - GROWING DEMAND AS WIND- AND PHOTOVOLTAIC-GENERATED POWER CONTINUES TO INCREASE}

To achieve their full profitability over the lifetime of the plant, power plants need to be optimized for future market potentials and needs. Attractive potentials can still be expected in this market of short-term demand coverage, despite the fact that since about 2010 photovoltaic installations having increasingly been cutting into demand peaks over the midday hours and therefore the peak-load margin potential. The VDE40 Study (Figure 7) forecasts demand peaks of up to $35 \mathrm{GW}$ at operating windows of under four hours. Pitted against this demand stands a fleet of peak-load power plants with a combined generating capacity of about $10 \mathrm{GW}$. Shortages in demand coverage must therefore be anticipated.

In contrast to the peaks in demand that regularly occur over the midday hours, today's demand arises from weather-dependent supply shortages caused, for example, by temporary shadowing from clouds or temporary lulls in the wind. Because these weatherrelated events can impact the entire fluctuating fleet of renewable energy resources, we will be confronted in Germany with a peak-load demand in the double-digit GW range.

Especially for cogeneration plants that remain online to supply heat, there are opportunities to serve these market windows by quickly ramping up power production from partial-load operation, because no startup costs are incurred in these cases. This makes the marginal costs of covering demand significantly lower than for units that are intended to serve this market from a standby condition. What's more, the gas turbine can be used to cover peak load even in summer if a bypass stack is provided between the gas turbine outlet and HRSG to allow only gas turbine operation with no water-steam cycle.

For heating operations, unit output can be increased by providing a modest level of supplementary firing. This slight supplementary firing barely influences unit efficiency in normal operation because operating pressure stays close to the optimized values in the design case. If higher supplementary firing of the HRSG is implemented, however, swallowing capacity of the steam turbine to accommodate the change must be increased. This entails a drop of life steam pressure as well as in efficiency when the plant is operated without supplementary firing.

\section{BALANCING POWER MARKET}

Forecasting the coming trends in balancing power markets is a significantly more complex affair than in the energy-only market, which can be projected with relative precision based on the extensive studies of future residual-load demand. Despite this accuracy, however, a number of scenarios and studies are currently the 


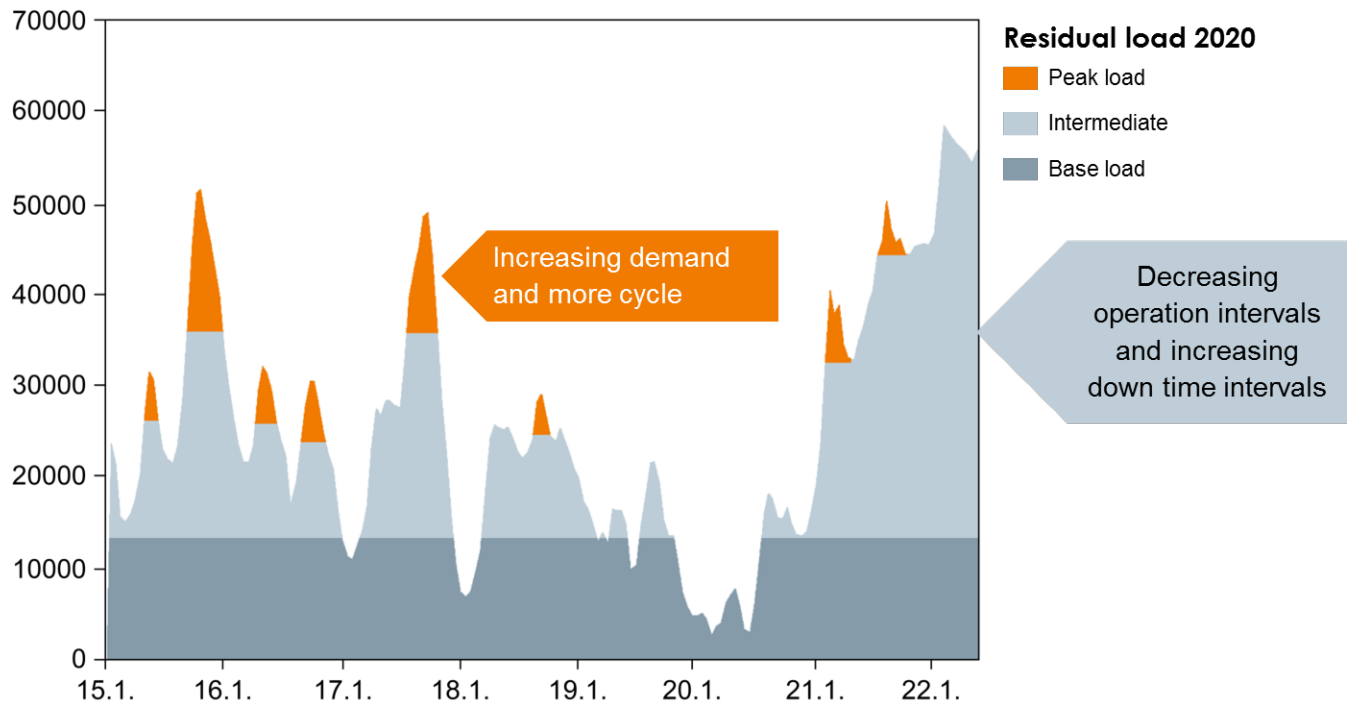

Figure 7. Residual-load demand 2020 - Expected growth in the peak-load operating range.

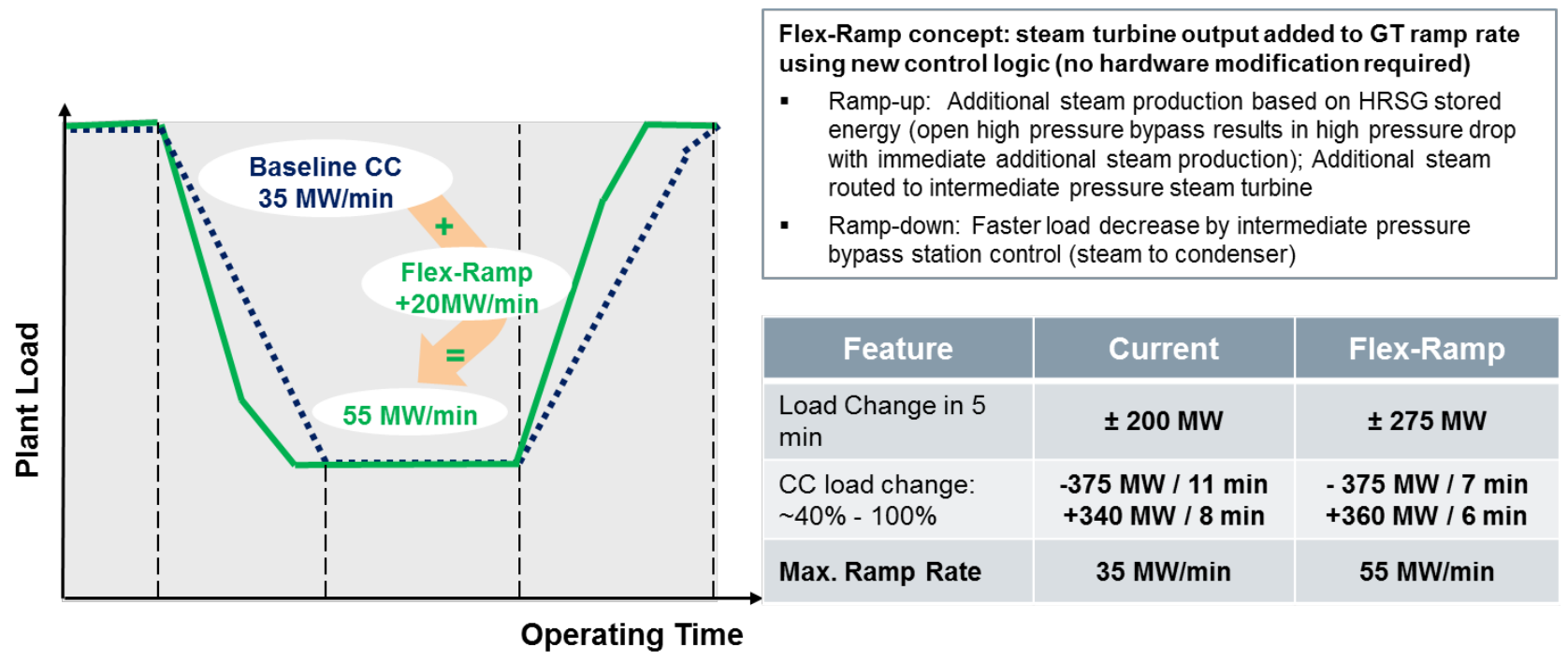

Figure 8. Load Ramp Test at Lausward CHP Station.

subject of discussion. It is plainly apparent that the business potentials of individual plants depend to a great extent on location and grid expansion.

It can generally be assumed that grid services in the future will become increasingly more important to power generation contributing to demand coverage. While most scenarios assume that a major share of the primary frequency control will be provided by controllable consumers, in the case of the control reserves the picture is somewhat different. When renewable energy sources are unable to deliver adequate power feed-in to the grid, the higher marginal costs of fossil-fuel power plants taking up the slack will lead to higher electricity prices. It's therefore likely that a portion of the controllable consumption will be reduced to a minimum. These capacities will therefore be removed from the market as positive control reserve, and will no longer be able to take part in covering grid loads. If power supply shortages occur that need to be com- pensated by the control reserve, fossil-fired units will have to cover this demand. This means that, if the fossil-fired units are currently in operation, the control reserve market offers opportunities to maximize the margin.

We achieve an increase in the load-change gradients that allow marketing of a higher control reserve using our FlexRamp technology. The load-change gradient of a combined cycle power plant is determined by the combined ramping speeds of the gas turbine and steam turbine. In order to achieve the highest possible overall gradient, the gas turbine load is changed at the highest possible and technically allowable gradient.

If a ramp-up in output is desired, in parallel and simultaneous with running up the gas turbine as quickly as possible, the steam turbine's output is significantly higher than is conventionally possible in traditional combined cycle power plants. By temporarily opening bypass valves, energy stored in the HRSG in the form 
of additional steam from the high-pressure section of the HRSG is suddenly admitted to the intermediatepressure section of the steam turbine, which results in a considerable change in steam turbine output. This boost is only available for a short time, because after a few minutes the extra energy stored in the HRSG is consumed by the additional steam extraction. This brief time span of just a few minutes is enough, however, to sustainably bring the HRSG up to the new load level using the increased exhaust heat of the gas turbine.

When rapid drops in power must be achieved, the load reduction in the steam turbine is greatly accelerated by routing the intermediate-pressure steam to the condenser via a bypass station.

These measures allow operators to implement upward and downward load ramps of up to $55 \mathrm{MW}$ per minute. In test runs, so-called multiple double-hump curves were used to demonstrate that this fast ramping is not only possible on a one-time or limited basis; it can also be executed stably and reliably in the rapid sequencing of upward and downward load changes during continuous operation.

If supplementary firing is considered in the plant design to cover peak loads, the nominal output can be maintained by supplementary firing in the frequency control mode, while gas turbine output is maintained at a level that demonstrates adequate control reserve capacity. While this leads to a slight drop in efficiency, this only occurs during peak-load demand. In the United States, where supplementary firing designs are customarily used, these control concepts are already being implemented.

\section{Forecasting FUtURE CONTROL REGIMES}

A number of flexibilization measures are available to optimize cogeneration plants and thereby maximize the plants' economic value for the future. The question is how to determine what package is optimally suited for the given location and the specific application. Until recently, design engineers had attempted to derive a deployment plan from forecasts of the extrapolated residual loads. However, this prognostic approach is unable to meaningfully consider location-specific parameters. That's why Siemens has developed a forecasting model that can represent the entire power plant fleet and all supply lines. This tool enables the computation of an initial prognosis of a plant's future deployment plan. It even allows meaningful advance analyses of the profitability of grid services based on the supply grid model, including grid deficiencies. The forecast itself is based on a purely market-economy approach. Retrospective analyses of these forecasts reveal that they accurately reflected actual operation 90 percent of the time. Work is currently underway to improve the tools' prognostic accuracy.

Once the operating regime has been determined, a feature configurator can be used to compile the optimal package of individual flexibilization measures. This enables solution packages to be offered that are optimally customized to individual business cases.

\section{Fortuna - THE MOST EFFICIENT COGENERATION PLANT IN THE WORLD}

While these approaches look very promising in theory, are there any reference projects for the new features? The new Fortuna power plant unit installed at Lausward Power Station in Düsseldorf's inland harbor is a cutting-edge combined cycle power plant with a performance capacity far exceeding those customarily achieved by power generating units of this type. By using innovative technologies, state-of-the-art engineering, and our pooled expertise for optimal power plant solutions, we are ensuring that environmentfriendly electric power and district heat can be generated economically for a low-carbon future.

The highest efficiency: Fortuna's 61.5 percent electrical efficiency exceeds even our previous world record of 60.75 percent set by the Ulrich Hartmann combined cycle unit at Irsching Power Station in southern Germany. A triple-pressure Benson ${ }^{\circledR}$ heat-recovery steam generator that achieves steam temperatures of $600{ }^{\circ}$ Celsius at 170 bar is one element that makes this high electric efficiency rating possible.

The best possible use of waste heat: To supply the city of Düsseldorf with district heat, steam is extracted from the low-pressure steam turbine section at volumes of $300 \mathrm{MW}$ of thermal energy in combined cycle operation. The plant's high electrical efficiency combined with its efficient use of heat generated in the power production process (in combined heat and power generation, otherwise known as cogeneration) increases the overall fuel efficiency of the natural gas to 85 percent.

Energy efficiency was further improved by optimizing startup and shutdown procedures. The newest generation of Co-Start technology has been successfully implemented. As a result, startup time for hot starts has been shortened from 50 minutes to less than 25 minutes. This translates to significant fuel savings by increasing efficiency during startup, which also reduces the associated $\mathrm{CO}_{2}$ emissions. Assuming that 200 hot starts will be run per year, this amounts to savings of $€ 1.1$ million in fuel costs alone.

The Co-Start technology has also been implemented for warm starts. This has enabled startup time to be halved, reduced from the conventional 90 minutes to 45 minutes. And just as for hot starts, this results in fuel savings. Unit cost-effectiveness and therefore profitability are improved thanks to the lower fuel costs. With 50 warm starts per year, this will produce savings of some $€ 400,000$.

However, the potential for improvement is not just for startups: Because power plant units also consume fuel during shutdown procedures, using Quick-Stop 

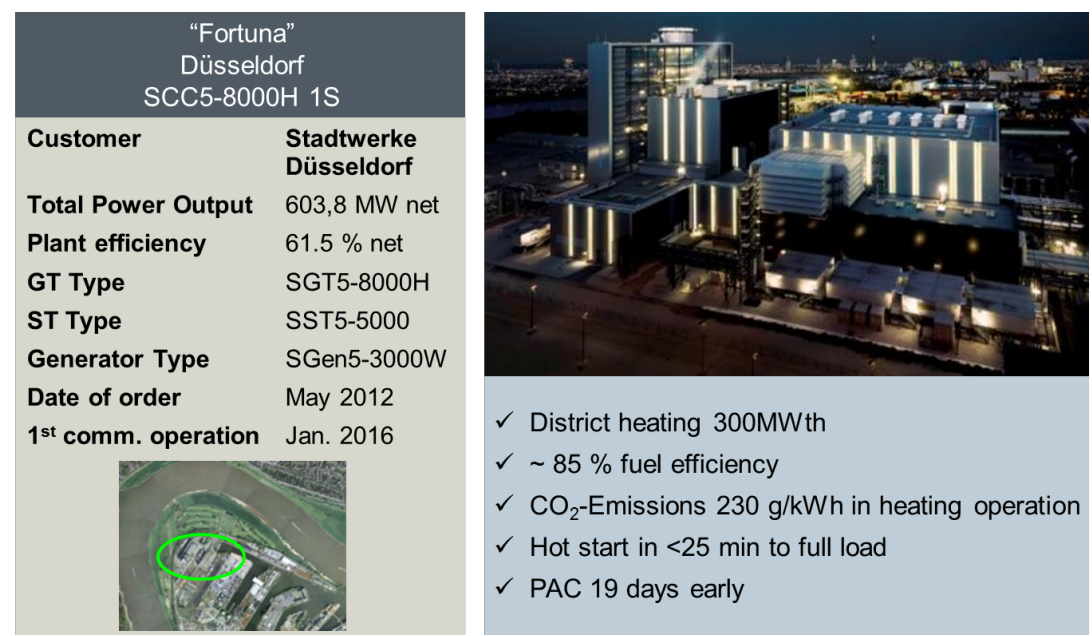

Figure 9. Fortuna Power Station, Düsseldorf, Germany.

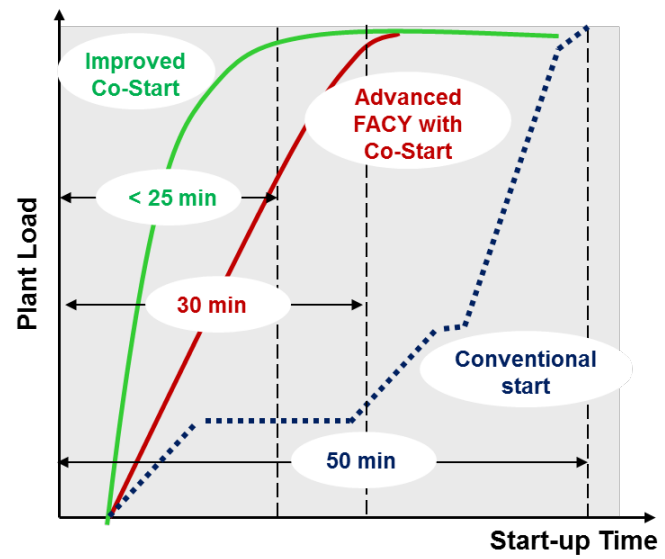

Co-Start concept: Further improvement without hardware modification

- Shortest start-up time and higher flexibility

- Lower fatigue for Steam Turbine

- Higher Dispatch rate, due to short start-up times

\begin{tabular}{|l|c|c|c|}
\hline \begin{tabular}{|l|c|} 
Start-up \\
time
\end{tabular} & $50 \mathrm{~min}$ & $30 \mathrm{~min}$ & $25 \mathrm{~min}$ \\
\hline Fuel [kg] & 32.600 & 20.000 & 16.050 \\
\hline Fuel [MWh] & $\mathbf{4 2 0}$ & $\mathbf{2 6 0}$ & $\mathbf{2 1 0}$ \\
\hline Fuel [€] & 10500 & $\mathbf{6 5 0 0}$ & $\mathbf{5 2 5 0}$ \\
\hline Delta [\%] & 100 & $\mathbf{6 2}$ & $\mathbf{5 0}$ \\
\hline
\end{tabular}

Figure 10. Hot Co-Start Test at Lausward CHP Station.

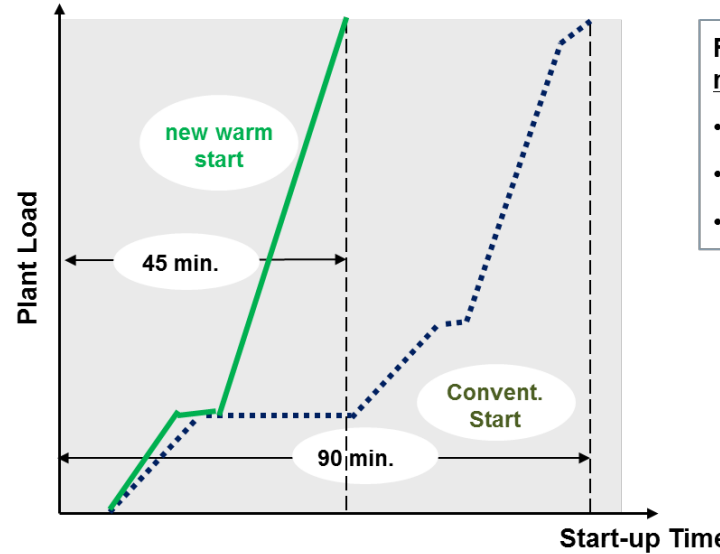

\section{Further improvement without hardware} modification

- Shortest start-up time and higher flexibility

- Use low energy prices to keep system warm

- Higher Dispatch rate, due to short start-up times

\begin{tabular}{|l|c|c|}
\hline \multicolumn{1}{|c|}{ Start Time } & $90 \mathrm{~min}$ & $45 \mathrm{~min}$ \\
\hline Fuel $[\mathrm{kg}]$ & 55,900 & 29,700 \\
\hline Fuel $\left[\mathrm{MWh}_{\text {th }}\right]$ & 720 & 380 \\
\hline Fuel $[€]$ & 18,100 & 9,600 \\
\hline Delta $[\%]$ & 100 & 53 \\
\hline
\end{tabular}

Figure 11. Warm Co-Start Test at Lausward CHP Station. 


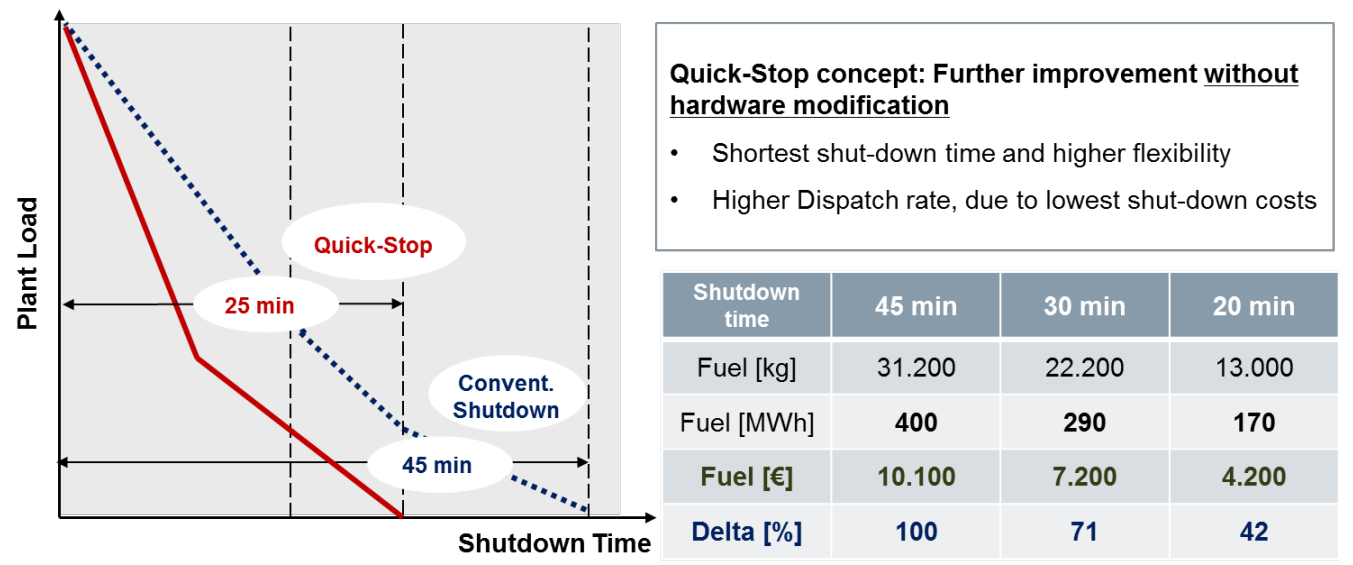

Figure 12. Quick-Stop Test at Lausward CHP Station.

technology and the reduction in shutdown time it achieves results in more fuel savings. Shutdown optimization has reduced shutdown time from 45 to 25 minutes.

The Fortuna power plant project implemented by the municipal utility Stadtwerke Düsseldorf in collaboration with Siemens makes clear the success factors that are vital to building and operating a new power plant in Germany's challenging market today.

\section{Conclusions}

The transition of our energy mix is placing greater focus on energy efficiency. Lawmakers have already recognized that combined heat and power generation (cogeneration) can help increase energy efficiency. Targeted promotion and subsidization have raised the cost-effective profitability of cogeneration plants to a range that is already conducive to investment.

But how can the economic value of this investment be maximized? To find the answer, Siemens developed a number of tools that enable the forecasting of future operating regimes and the assessment of each individual flexibilization measure in terms of return on investment.

Above all, it can be assumed that to provide useful heat, it will be absolutely necessary to decouple power generation from the supplying of heat. Design engineers are banking on power-driven plant designs that, solely in power-generation mode, can use all the waste heat to generate electric power in a downstream condensing turbine. Efficiencies of over 61 percent in power-generation operating mode have already been achieved by the Fortuna project. In the changed operating regime, energy efficiency doesn't just focus on the nominal load case alone. Even startup and shutdown procedures can be optimized for greater efficiency.

Plant designs with no peak-load reserves still dominate the market. Given the forecasted market developments, designs incorporating supplementary firing with a control concept optimized in line with grid service are becoming more attractive. These designs enable plant operators to exploit business potential in the peak-load market while at the same time generating revenue from the balancing power markets.

Last but not least, the summer season can be used to generate sales and profit margin. By relying on a power-driven configuration, the plant can be positioned in the intermediate-load market. What's more, implementing a bypass stack enables plants to run up from the shutdown condition to position themselves on the peak-load market.

\section{Disclaimer}

This document contains statements related to our future business and financial performance and future events or developments involving Siemens that may constitute forward-looking statements. These statements may be identified by words such as "expect," "look forward to," "anticipate" "intend," "plan," "believe," "seek," "estimate," "will," "project" or words of similar meaning. We may also make forward-looking statements in other reports, in presentations, in material delivered to shareholders and in press releases. In addition, our representatives may from time to time make oral forward-looking statements. Such statements are based on the current expectations and certain assumptions of Siemens' management, of which many are beyond Siemens' control. These are subject to a number of risks, uncertainties and factors, including, but not limited to those described in disclosures, in particular in the chapter Risks in the Annual Report. Should one or more of these risks or uncertainties materialize, or should underlying expectations not occur or assumptions prove incorrect, actual results, performance or achievements of Siemens may (negatively or positively) vary materially from those described explicitly or implicitly in the relevant forward-looking statement. Siemens neither intends, nor assumes any obligation, to update or revise these forward-looking statements in light of developments which differ from those anticipated. 
Trademarks mentioned in these documents are the property of Siemens AG, its affiliates or their respective owners.

\section{References}

[1] A. Pickard, F. Strobelt. Development trends in cogeneration and combined heat and power plants. In POWER-GEN Europe, Milano, Italy. 2016. 